\title{
Cloning of Prepro-Adrenomedullin and mRNA Expression in Cats
}

\author{
Nobuyuki KANNO ${ }^{1,2) *}$, Kazushi ASANO ${ }^{1)}$, Kenji TESHIMA ${ }^{1)}$, Mamiko SEKI ${ }^{1)}$, Kazuya EDAMURA ${ }^{1)}$ and \\ Shigeo TANAKA ${ }^{1)}$ \\ ${ }^{1)}$ Laboratory of Veterinary Surgery, Department of Veterinary Medicine, College of Bioresource Sciences, Nihon University, 1866 \\ Kameino, Fujisawa, Kanagawa 252-8510 and ${ }^{2}$ Laboratory of Veterinary Surgery, Department of Veterinary Medicine, Faculty of \\ Agriculture, Miyazaki University, 1-1 Gakuen Kibanadai Nishi, Miyazaki 889-2192, Japan
}

(Received 5 November 2009/Accepted 16 April 2010/Published online in J-STAGE 1 May 2010)

\begin{abstract}
The objective of this paper was to evaluate the sequence of feline prepro-adrenomedullin (AM) and its tissue distribution and to investigate whether expression of feline AM mRNA increases in association with spontaneous cardiomyopathy. The feline preproAM cDNA sequence and deduced amino acids were 564 base pairs and 188 residues, respectively. The cDNA sequences of feline prepro-AM including AM and proadrenomedullin N-terminal 20 peptide showed high homology with those of other mammalian species. The mRNA expression of AM was detectable in various normal tissues. The mRNA levels of AM were elevated in hearts with cardiomyopathy compared with normal hearts. This study suggests that AM has an important role as a neurohumoral factor in cats with spontaneous heart diseases.

KEY WORDS: adrenomedullin, cardiomyopathy, feline, proadrenomedullin N-terminal 20 peptide.
\end{abstract}

J. Vet. Med. Sci. 72(10): 1345-1349, 2010

Adrenomedullin (AM) is a potent vasorelaxing and natriuretic peptide that was isolated from human pheochromocytoma [12]. It has one intramolecular disulfide bond and the common structure of the calcitonin gene related peptide superfamily. In addition, another bioactive peptide was found to be proceeded from N-terminal portion of prepro$\mathrm{AM}$, and this peptide was decided proadrenomedullin N-terminal 20 peptide (PAMP). PAMP inhibits sympathetic neural transmission whereas AM directly dilates vascular smooth muscles [20].

AM has been demonstrated to be synthesized and secreted mainly by endothelial cells, vascular smooth muscle cells and fibroblasts in humans [2, 6, 21, 22]. The expression levels of AM mRNA have been shown to be the highest among various tissues under cardiovascular pathological conditions, and the circulating AM concentration has also been demonstrated to increase in some cardiovascular disorders including ischemic heart disease, cardiomyopathy, pulmonary hypertension and congestive heart failure $[3,5$, $9,11]$. Therefore, AM has been assumed to play an important role in circulatory regulation similar to natriuretic peptide and other neurohormones, and has been expected to be used as a diagnosis and prognosis tool. In addition, it may also be useful as a therapeutic agent in patients with hypertension and cardiac diseases [16, 24].

The nucleotide and amino acid sequence of AM have been established for many species including the human, bovine, porcine, canine, rat and mouse $[1,13,14,18,19]$. To our knowledge, however, the feline prepro-AM gene and amino acid sequence have not been determined, and there

\footnotetext{
* Correspondence to: Kanno, N., Laboratory of Veterinary Surgery, Department of Veterinary Medicine, Faculty of Agriculture, Miyazaki University, 1-1 Gakuen Kibanadai Nishi, Miyazaki 889-2192, Japan.

e-mail:nkanno@cc.miyazaki-u.ac.jp
}

are no reports on the synthesis of feline AM in various tissues. In addition, no studies have demonstrated the expression of feline AM in the myocardial tissue of patients with spontaneous cardiac diseases. This study was carried out to examine the molecular cloning of feline prepro-AM and its tissue distribution and to investigate AM mRNA expression in the feline myocardium with and without cardiomyopathy.

The two healthy mix cats were used to determine the sequence and tissue distribution and two privately owned cats with spontaneous cardiac disease were used for comparison between the normal and diseased myocardium.

The normal two cats were confirmed to be healthy on the basis of physical examination, complete blood count and serum biochemical profile. They were sacrificed by intravenous administration of an overdose of barbiturate and potassium chloride. These cat specimens were frozen by immersion in liquid nitrogen and stored at $-80^{\circ} \mathrm{C}$ until use.

Two cat patients that were definitively diagnosed with hypertrophic cardiomyopathy (HCM) in the primary care hospital were obtained as samples. Cats were diagnosed with HCM by echocardiography, if the intaraventricular septal end-diastolic thickness and/or left ventricular posterior wall end-diastolic thickness were $>6 \mathrm{~mm}$ (Table 1) [4]. In addition, the cats had aortic thrombosis. Autopsy was performed with consent from the owners immediately after the cats died. Cardiac tissue specimens of the left atrium (LA) and left ventricle (LV) were obtained from each cat. These samples were fixed in $10 \%$ formalin in the primary care hospital, and the samples were transported to Nihon University. All cats were cared for according to the principles outlined in the Guide for the Care and Use of Laboratory Animals approved by the College of Bioresource Sciences, Nihon University.

Total RNA was extracted from normal LV specimens using an RNA isolation kit in accordance with the manufac- 
Table 1. Age, body weight and echocardiographic data of the cats included in the study

\begin{tabular}{lccc}
\hline & Control & \multicolumn{2}{c}{ HCM } \\
\cline { 2 - 4 } & & No. 1 & No. 2 \\
\hline Age (year) & $11 \pm 2.4$ & 12 & 9 \\
BW (kg) & $3.8 \pm 0.6$ & 4.8 & 2.6 \\
IVSd (mm) & $5.1 \pm 1.0$ & 6.9 & 6.7 \\
LVPWd (mm) & $4.9 \pm 1.2$ & 5.9 & 6.1 \\
LA/Ao & $1.3 \pm 0.1$ & 1.38 & 1.7 \\
MR & - & + & + \\
\hline
\end{tabular}

BW, body weight; IVSd, intaraventricular septal end-diastolic thickness; LVPWd, left ventricular posterior wall end-diastolic thickness; LA, left atrium; Ao, aorta; MR, mitral regurgitation.

turer's instructions (RNeasy kit; Qiagen Inc., Valencia, CA, U.S.A.). First-strand cDNA was generated from $2 \mu \mathrm{g}$ of the total RNA as a template. Reverse transcription (RT) was performed using reverse transcriptase (Omniscript Reverse Transcriptase kit; Qiagen Inc.).

Oligo(dT) primer was used to amplify the 3'-poly(A) tails of the mRNA as a first-strand priming method. To amplify feline AM cDNA fragments, we designed oligonucleotide primers (Table 2) on the basis of the known canine AM sequences (GenBank/EMBL/DDBJ accession No. AF045773), respectively. A PCR assay was performed using commercially available Taq polymerase (TaKaRa Taq; Takara Bio Inc., Kyoto, Japan). The thermal profile consisted of predenaturing at $94^{\circ} \mathrm{C}$ for $5 \mathrm{~min} ; 35$ cycles of a denaturation step at $94^{\circ} \mathrm{C}$ for $45 \mathrm{sec}$, an annealing step at $64^{\circ} \mathrm{C}$ for $45 \mathrm{sec}$ and an extension step of $72^{\circ} \mathrm{C}$ for $1 \mathrm{~min}$; and finally, an extension procedure at $72^{\circ} \mathrm{C}$ for $10 \mathrm{~min}$. Each PCR product was electrophoresed through a $2.0 \%$ agarose gel and stained with ethidium bromide for visualization. The PCR products were ligated into TA cloning vectors (pCR 2.1-TOPO; Invitrogen Corp., Carlsbad, CA, U.S.A.). The plasmid DNA from each sample was purified in accordance with the manufacturer's instructions (Quantum Prep Plasmid Miniprep kit; Bio-Rad Laboratories, Hercules, CA, U.S.A.) and sequenced by the dideoxy chain termination method (BigDye Terminator v3.1 Cycle Sequencing kit; Applied Biosystems, Foster City, CA, U.S.A.). Sequence results were compared with those of other mammalian species in the GenBank data bank at the National Center for Biomedical Information.

Total RNA was extracted from the 25 samples of the fol- lowing various tissues of the two normal cats: left atrial appendage (LAA), right atrial appendage (RAA), LA, right atrium (RA), LV, right ventricle (RV), aorta, lung, liver, pancreas, spleen, renal cortex, renal medulla, adrenal gland, thyroid grand, skeletal muscle, urinary bladder, lymph node, esophagus, small intestine, large intestine, cerebellum, cerebrum, medulla oblongata and pituitary grand.

Synthesis of first-strand cDNA was performed using $2 \mu \mathrm{g}$ of the total RNA as a template. To amplify cDNA fragments of feline AM, we designed oligonucleotide primers (Table 2) on the basis of the feline AM sequences determined in this study. To amplify the feline glyceraldehyde3-phosphate dehydrogenase (GAPDH) as an internal reference, we designed oligonucleotide primers based on known sequences (Table 2). The thermal profile was carried out as follows: predenaturing at $94^{\circ} \mathrm{C}$ for $1 \mathrm{~min}, 35$ (for $\mathrm{AM}$ ) cycles or 30 cycles (for GAPDH) of a denaturation step at $94^{\circ} \mathrm{C}$ for $45 \mathrm{sec}$, an annealing step at $66^{\circ} \mathrm{C}$ (for $\mathrm{AM}$ ) or $64^{\circ} \mathrm{C}$ (for GAPDH) for $45 \mathrm{sec}$ and an extension step of $72^{\circ} \mathrm{C}$ for 1 min; and a final extension procedure at $72^{\circ} \mathrm{C}$ for $8 \mathrm{~min}$. All PCR products were electrophoresed through a $2.0 \%$ agarose gel and stained with ethidium bromide for visualization.

To compare normal and cardiomyopathy hearts, RNA extracts was subjected to RT-PCR. As described previously [15], the samples of tissue were homogenized, digested by proteinase $\mathrm{K}$ and incubated at $55^{\circ} \mathrm{C}$ for $1 \mathrm{hr}$, because the samples were treated with formalin. RT-PCR was performed using the above methods.

The cDNA sequence corresponding to the coding region of the feline prepro-AM was 564 base pairs (bp), and the deduced AM protein contained 188 amino acids. In addition, prepro-AM contains PAMP (20 amino acid) and AM (52 amino acid). The coding sequence begins with the putative initiation code (ATG, doubled line), while a terminal codon is found at nucleotide 565-567 (Fig. 1).

The homologies of the nucleic and amino acid sequences of AM among some mammalian species were calculated (Fig. 2, Table 3). Feline AM showed high homologies with other mammalian species at the nucleic and amino acid levels. The highest AM homology (95.51\%) was between the feline and canine at the nucleic acid level. At the amino acid level, the feline AM had 100\% homology with porcine AM. Similar to AM, feline PAMP showed high homologies with other mammalian species. The highest homology (98.33\%) for PAMP was between the feline and bovine. However, at the amino acid level, PAMP showed 100\% homology

Table 2. Primer sequences used to sequence feline cDNA

\begin{tabular}{llll}
\hline Primer pair & Orientation & \multicolumn{1}{c}{ Primer sequence } & Purpose \\
\hline AM1 & Forward & 5'-GCCACCTCTGGTTTCTCAC-3' & Cloning \\
& Reverse & 5'-TGTCATTGTCTGTGAACTGGTA-3' & \\
AM2 & Forward & 5'-GCGCACCAGATCTACCAGTT-3' & Cloning \\
& Reverse & 5'-CACCCCGTGAGAAATCAGTT-3' & \\
AM3 & Forward & 5'-GCCAACCCAGACTCTCATTC-3' & RT-PCR \\
& Reverse & 5'-GTCCTTGTCCGTGAACTGGT-3' & \\
GAPDH & Forward & 5'-GGAGAAAGCTGCCAAATACG-3' & \multirow{2}{*}{ RT-PCR } \\
& Reverse & 5'-ACCAGGAAATGAGCTTGACA-3' & \\
\hline
\end{tabular}




\begin{tabular}{|c|c|c|}
\hline-180 & GAAAAGTGGTTTCTTGGTGACACTAGCCGGAACAGCTCCAGCCTTGCСACCTC & -12 \\
\hline-120 & GGTT TCTCACCGСGGСTTGGACGG TGGGGT TITGCCAGTGCС AGAGCGACGTCTCAGAC & -61 \\
\hline-60 & 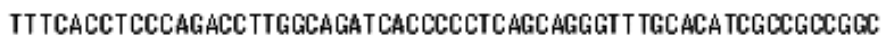 & -1 \\
\hline 1 & AIGAAGCTGGTTCCCG TCGCCC TCA TGTACC TGGGCTCCC TGGCCT TCT TGGGCGGGGAC & 60 \\
\hline 1 & HETLysLeuYa IP roVal A laLeuMET TyrLeuG IySerLeuA IaPheLeuG Iy A laAsp & 20 \\
\hline 61 & АС TGCACGGCTCGACG TGGCGTCAGAGT TCCGAAAGAAATGGAATAAGTGGGCTCTAAGT & 186 \\
\hline 21 & Thr $\frac{\text { Al aArgLeuAspValA a aSerG luPheArgLysLysTrpAsnLysTrpAlaLeuSer }}{\text { PAMP }}$ & 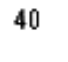 \\
\hline 121 & CGTGGCAAGAGGGAACTTCGGGTGTCCA & 180 \\
\hline 41 & 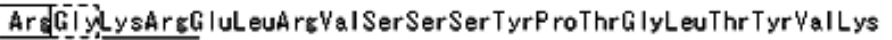 & 60 \\
\hline 181 & GCCGGGCCAACCCAGACTCTCATTCGGCCCC & 240 \\
\hline 61 & Al aG I y ProThrG InThrLeuI leArgP ro & 80 \\
\hline 241 & GAAC & 300 \\
\hline 81 & GInA| aSerSerProAspA IaA IaA rg' & 100 \\
\hline 301 & AACTG & 360 \\
\hline 101 & AsnPheG |nG | yLel & 120 \\
\hline 361 & $\overline{G G G A C A A G}$ & 420 \\
\hline 121 & AlaHisGinIleTyrGInPheThrAspLysA & 140 \\
\hline 421 & ATTAGCCCCD & 480 \\
\hline 141 & 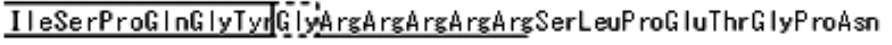 & 160 \\
\hline 481 & CAG & 540 \\
\hline 161 & TrpThrLeuSer & 180 \\
\hline 541 & TAT & 600 \\
\hline 181 & ValLeuAspThrLeuLeuLysValw* & 188 \\
\hline 601 & $\operatorname{CLA}$ & 680 \\
\hline 661 & GGAGACCG & 720 \\
\hline 721 & GAGCCCTGG & 780 \\
\hline 781 & GGCCCAGGTGCCCCGTGGGGGCAGAAGAATGTGAGGGAGTGTCT & 840 \\
\hline 841 & GCACACTG & 900 \\
\hline
\end{tabular}

Fig. 1. Nucleotide sequence of feline prepro-adrenomedullin (AM) cDNA . Numbers on the left correspond to the nucleotide and amino acid numbers. The cDNA sequence corresponding to the coding region of the prepro-AM was 564 base pairs (bp). The deduced AM protein contained 188 amino acids. The coding sequence contains the putative initiation codon (ATG, double underline). The termination codon is shown by three consecutive asterisks. PAMP ( 22 to 41 residues) and AM (95 to 146 residues) are boxed, with dashed boxes denoting $\mathrm{C}$-terminal glycine, which gives rise to $\mathrm{C}$-terminal amidated amino acids.

between the feline and human.

AM mRNA expression was detected in the heart including the atrial appendage, atrium and ventricle. In addition, expression of AM mRNA was detectable in various tissues including the lung, renal, adrenal gland, thyroid gland, skeletal muscle, urinary bladder and brain in the healthy cats (Fig. 3). To evaluate the role AM in cats with heart diseases, we compared the cardiac AM mRNA level in the normal and HCM cats (Fig. 4). There were no significant differences in AM mRNA expression between the atrium and ventricle in the healthy cats. In addition, the AM mRNA expression level was higher in diseased hearts, especially in the LA and LV in cat No. 2 with cardiomyopathy compared with the normal cats.
The AM gene and amino acids in the animals were comparatively saved, and the AM structure would be conserved. Interestingly, among 52 bases of the feline AM amino acid sequences, feline AM showed $100 \%$ homology with porcine AM. In addition, only one amino acid base was different between human AM and feline AM, and PAMP showed 100\% homology with human PAMP.

The tissue distributions of feline AM mRNA were determined in the two healthy cats, and the expression of feline AM mRNA was found to be detectable in 25 normal tissues. AM mRNA is widely synthesized in adult healthy cats. Higher expression was found in the heart, renal, adrenal gland, thyroid gland, skeletal muscle, urinary bladder and brain. The relative intensities of AM mRNA in feline tis- 


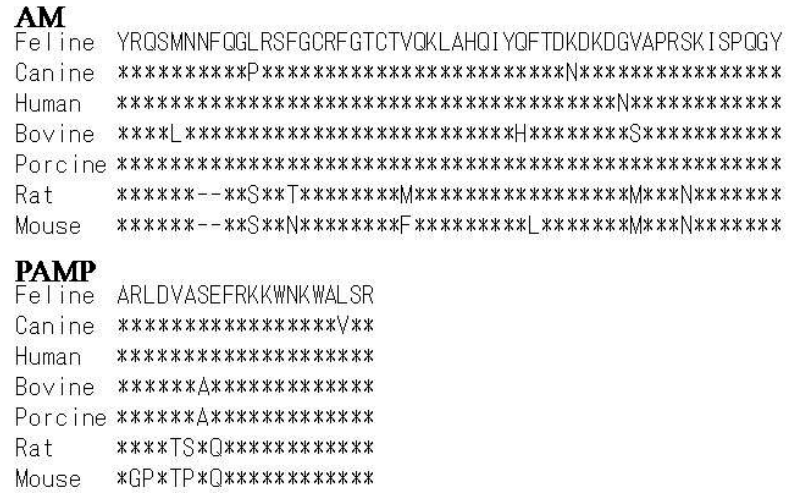

Fig. 2. Comparison of the amino acid sequence of feline and other mammalian AM and PAMP with mammalian species. Asterisks $(*)$ show the same amino acid as in the feline.

sues are similar to those in human, dog and porcine tissues $[10,12,13]$. In a previous study, the AM mRNA transcript was detected most strongly in pheochromocytoma tissue, followed by the adrenal medulla, cardiac ventricle and lung, and weaker expression was detected in the renal [12]. In porcine tissues [13], the expression was detected most strongly in the lung and renal as well as in the adrenal medulla. In rat tissues [19], the expression was strongest in the lung, followed by the adrenal glands, heart, spleen, renal, duodenum and submandibular glands. In this study, a higher level of AM mRNA was obtained in the brain. In addition, there was no obvious difference between the atrium and ventricle in the normal cats, whereas it is known that AM mRNA expression is higher in the atrium than in the ventricle in normal [8]. These results suggested that there were slight differences in the pattern of AM gene expression among species or conditions. Because AM mRNA is present in various tissues, AM production might be regulated not only by the heart itself but also by generalized homeostasis in the individual animal.

In this study, AM mRNA expression was revealed to be increased in heart tissues from cats with spontaneous HCM. In particular, the increasing rate of LV expression was higher than that of the atrium in the cats with HCM. These results are consistent with previous reports that ventricular AM expression proved to be activated during the progression of experimental congestive heart failure produced by rapid ventricular pacing in dogs and that atrial AM expres- sion was unchanged compared with the normal heart $[7,8]$. In addition, the plasma AM levels in hypertensive patients with left ventricular hypertrophy have been reported to be higher than in patients without hypertrophy [23]. In our study, AM mRNA expression in LA myocardium was increased in cat No. 2 cat with HCM, whereas it made no difference in No. 1, and the enlargement of the LA in No. 2 was greater than that in No. 1. It has been reported that AM mRNA expression in the LA significantly increases in dogs with mitral regurgitation [10]. Thus, AM may also reflect clinical conditions including atrium and ventricle loading in cats with heart disease. Further investigations are required to establish augmented feline AM production in a variety of heart diseases.

There were several limitations of this study. The patients had been prescribed therapeutic agents as needed. These agents may have affected AM mRNA expression in the myocardium. In addition, we used samples treated with formalin, and this method affects extraction of RNA. However, we were able to collect sufficient quantities of total RNA. Finally, the number of cases of HCM cats used in this study was small. Thus, additional study is needed to clarify the variation in AM expression in cats with heart disease.

In conclusion, the sequence of feline prepro-AM had high homology with other mammalian species. Moreover, AM was found to be detectable in tissues, and AM production might be regulated not only by the heart itself but also by generalized homeostasis in the individual animal. In addition, feline AM was confirmed to increase in diseased hearts. Thus, AM may have an important role as a neurohumoral factor in cats with heart diseases.

\section{REFERENCES}

1. Barker, S., Wood, E., Clark, A. J. and Corder, R. 1998. Cloning of bovine preproadrenomedullin and inhibition of its basal expression in vascular endothelial cells by staurosporine. Life Sci. 62: 1407-1415.

2. Eto, T., Kato, J. and Kitamura, K. 2003. Regulation of production and secretion of adrenomedullin in the cardiovascular system. Regul. Pept. 112: 61-69.

3. Etoh, T., Kato, J., Takenaga, M., Imamura, T., Kitamura, K., Koiwaya, Y. and Eto, T. 1999. Differential hormonal profiles of adrenomedullin and proadrenomedullin N-terminal 20 peptide in patients with heart failure and effect of treatment on their plasma levels. Clin. Cardiol. 22: 113-117.

4. Fox, P. R., Sisson, D. and Moise, N. S. 1999. Feline Cardiomy-

Table 3. Homologies of cDNA and amino acid sequences of Feline AM, and PAMP, compared with mammalian species

\begin{tabular}{lccccrrr}
\hline & \multicolumn{3}{c}{ Nucleic acid } & & \multicolumn{3}{c}{ Amino acid } \\
\cline { 2 - 3 } \cline { 7 - 8 } & CDS & AM & PAMP & & CDS & \multicolumn{1}{c}{ AM } & PAMP \\
\hline Human & $84.82 \%$ & $92.95 \%$ & $85.00 \%$ & & $84.88 \%$ & $98.08 \%$ & $100.00 \%$ \\
Porcine & $87.30 \%$ & $93.59 \%$ & $96.67 \%$ & & $83.07 \%$ & $100.00 \%$ & $95.00 \%$ \\
Bovine & $84.14 \%$ & $90.39 \%$ & $98.33 \%$ & & $82.80 \%$ & $94.23 \%$ & $95.00 \%$ \\
Canine & $89.93 \%$ & $95.51 \%$ & $93.33 \%$ & & $81.38 \%$ & $96.15 \%$ & $95.00 \%$ \\
Mouse & $71.20 \%$ & $77.42 \%$ & $78.33 \%$ & & $64.25 \%$ & $84.62 \%$ & $82.35 \%$ \\
Rat & $72.90 \%$ & $79.36 \%$ & $85.00 \%$ & & $64.21 \%$ & $86.54 \%$ & $85.00 \%$ \\
\hline
\end{tabular}




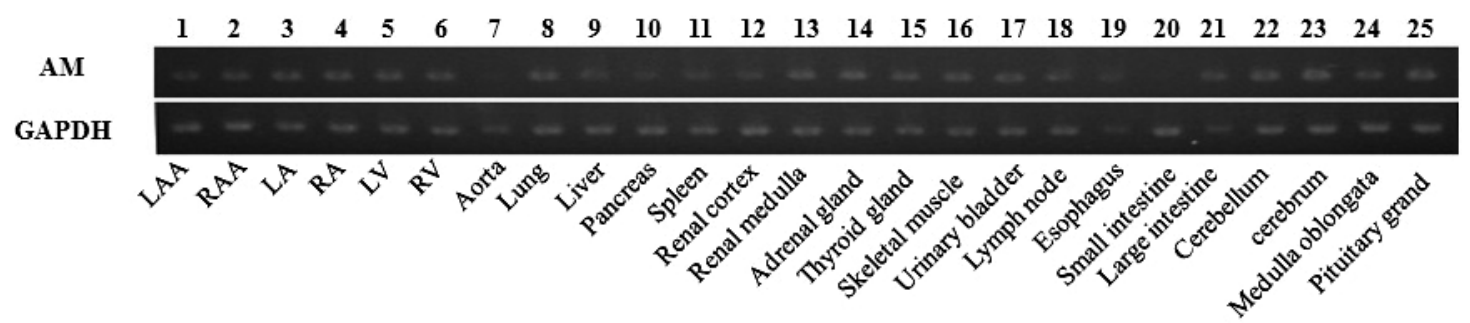

Fig. 3. Detection of AM mRNA expression in various normal feline tissues using RT-PCR. The expression of GAPDH was measured as an internal control.

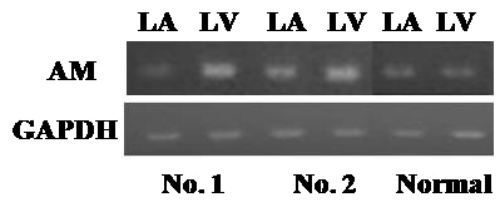

Fig. 4. Comparison of canine AM mRNA expression in normal hearts and cardiomyopathy (Nos. 1 and 2) by RT-PCR. The expression of GAPDH was measured as an internal control.

opathies. pp. 621-678. In: Textbook of Canine and Feline Cardiology, Principles and Clinical Practice, 2nd ed., WB Saunders, Philadelphia.

5. Ishimitsu, T., Nishikimi, T., Saito, Y., Kitamura, K., Eto, T., Kangawa, K., Matsuo, H., Omae, T. and Matsuoka, H. 1994. Plasma levels of adrenomedullin, a newly identified hypotensive peptide, in patients with hypertension and renal failure. $J$. Clin. Invest. 94: 2158-2161.

6. Isumi, Y., Minamino, N., Katafuchi, T., Yoshioka, M., Tsuji, T., Kangawa, K. and Matsuo, H. 1998. Adrenomedullin production in fibroblasts: its possible function as a growth regulator of Swiss 3T3 cells. Endocrinology 139: 2552-2563.

7. Jougasaki, M., Grantham, J. A., Redfield, M. M. and Burnett, J. C. Jr. 2001. Regulation of cardiac adrenomedullin in heart failure. Peptides 22: 1841-1850.

8. Jougasaki, M., Stevens, T. L., Borgeson, D. D., Luchner, A., Redfield, M. M. and Burnett, J. C. Jr. 1997. Adrenomedullin in experimental congestive heart failure: cardiorenal activation. Am. J. Physiol. 273: R1392-1399.

9. Kakishita, M., Nishikimi, T., Okano, Y., Satoh, T., Kyotani, S., Nagaya, N., Fukushima, K., Nakanishi, N., Takishita, S., Miyata, A., Kangawa, K., Matsuo, H. and Kunieda, T. 1999. Increased plasma levels of adrenomedullin in patients with pulmonary hypertension. Clin. Sci. (Lond.) 96: 33-39.

10. Kanno, N., Asano, K., Teshima, K., Kutara, K., Seki, M., Edamura, K., Kano, R., Hasegawa, A. and Tanaka, S. 2009. Gene expression of adrenomedullin in canine normal tissues and diseased hearts. J. Vet. Med. Sci. 71: 789-792.

11. Kato, J., Kobayashi, K., Etoh, T., Tanaka, M., Kitamura, K., Imamura, T., Koiwaya, Y., Kangawa, K. and Eto, T. 1996. Plasma adrenomedullin concentration in patients with heart failure. J. Clin. Endocrinol. Metab. 81: 180-183.

12. Kitamura, K., Kangawa, K., Kawamoto, M., Ichiki, Y., Nakamura, S., Matsuo, H. and Eto, T. 1993. Adrenomedullin: a novel hypotensive peptide isolated from human pheochromocytoma. Biochem. Biophys. Res. Commun. 192: 553-560.

13. Kitamura, K., Kangawa, K., Kojima, M., Ichiki, Y., Matsuo, H. and Eto, T. 1994. Complete amino acid sequence of porcine adrenomedullin and cloning of cDNA encoding its precursor.
FEBS Lett. 338: 306-310.

14. Kitamura, K., Sakata, J., Kangawa, K., Kojima, M., Matsuo, H. and Eto, T. 1993. Cloning and characterization of cDNA encoding a precursor for human adrenomedullin. Biochem. Biophys. Res. Commun. 194: 720-725.

15. Masuda, N., Ohnishi, T., Kawamoto, S., Monden, M. and Okubo, K. 1999. Analysis of chemical modification of RNA from formalin-fixed samples and optimization of molecular biology applications for such samples. Nucleic Acids Res. 27: 4436-4443.

16. Nishikimi, T., Yoshihara, F., Mori, Y., Kangawa, K. and Matsuoka, H. 2003. Cardioprotective effect of adrenomedullin in heart failure. Hypertens. Res. 26: S121-127.

17. Okazaki, T., Ogawa, Y., Tamura, N., Mori, K., Isse, N., Aoki, T., Rochelle, J. M., Taketo, M. M., Seldin, M. F. and Nakao, K. 1996. Genomic organization, expression, and chromosomal mapping of the mouse adrenomedullin gene. Genomics 37: 395-399.

18. Ono, Y., Kojima, M., Okada, K. and Kangawa, K. 1998. cDNA cloning of canine adrenomedullin and its gene expression in the heart and blood vessels in endotoxin shock. Shock 10: 243247.

19. Sakata, J., Shimokubo, T., Kitamura, K., Nakamura, S., Kangawa, K., Matsuo, H. and Eto, T. 1993. Molecular cloning and biological activities of rat adrenomedullin, a hypotensive peptide. Biochem. Biophys. Res. Commun. 195: 921-927.

20. Shimosawa, T., Ito, Y., Ando, K., Kitamura, K., Kangawa, K. and Fujita, T. 1995. Proadrenomedullin NH(2)-terminal 20 peptide, a new product of the adrenomedullin gene, inhibits norepinephrine overflow from nerve endings. J. Clin. Invest. 96: $1672-1676$.

21. Sugo, S., Minamino, N., Kangawa, K., Miyamoto, K., Kitamura, K., Sakata, J., Eto, T. and Matsuo, H. 1994. Endothelial cells actively synthesize and secrete adrenomedullin. Biochem. Biophys. Res. Commun. 201: 1160-1166.

22. Sugo, S., Minamino, N., Shoji, H., Kangawa, K., Kitamura, K., Eto, T. and Matsuo, H. 1994. Production and secretion of adrenomedullin from vascular smooth muscle cells: augmented production by tumor necrosis factor-alpha. Biochem. Biophys. Res. Commun. 203: 719-726.

23. Sumimoto, T., Nishikimi, T., Mukai, M., Matsuzaki, K., Murakami, E., Takishita, S., Miyata, A., Matsuo, H. and Kangawa, K. 1997. Plasma adrenomedullin concentrations and cardiac and arterial hypertrophy in hypertension. Hypertension 30: 741-745.

24. Troughton, R. W., Lewis, L. K., Yandle, T. G., Richards, A. M. and Nicholls, M. G. 2000. Hemodynamic, hormone, and urinary effects of adrenomedullin infusion in essential hypertension. Hypertension 36: 588-593. 